\title{
Thermal Stability of a Ni-Cr-W-Mo Alloy - Long-Term Exposures
}

\author{
L. M. Pike ${ }^{a}$, and S. K. Srivastava ${ }^{b}$ \\ Haynes International, 1020 West Park Ave., Kokomo, IN 46904-9013, USA \\ alpike@haynesintl.com, ${ }^{b}$ ksrivastava@haynesintl.com
}

Key words: 230 alloy, Ni-Cr-W-Mo, thermal stability, long-term exposure.

\begin{abstract}
HAYNES ${ }^{\circledR} 230^{\circledR}$ alloy, based on the Ni-Cr-W-Mo system, is extensively used in gas turbines and other applications at high temperatures. It is recognized that the microstructure of many alloys under long-term service conditions can change. Microstructural changes may affect mechanical properties which in turn may determine component design life in service. Given the importance and widespread usage of 230 alloy, a number of studies on its thermal stability have been conducted. This study will focus on the effect of long-term thermal exposures at temperatures ranging from 649 to $871^{\circ} \mathrm{C}\left(1200\right.$ to $\left.1600^{\circ} \mathrm{F}\right)$ on the microstructure and properties of 230 alloy. Room and elevated temperature tensile, and room temperature Charpy impact toughness properties of thermally exposed material are determined and correlated to observed changes in the microstructure. Microstructural analyses were performed using extraction/X-ray diffraction together with optical and scanning electron microscopy. The mode of fracture was ascertained by fractography of the thermally-exposed and broken test samples. The paper presents previously unpublished results for long-term exposures with durations ranging up to 50,000 hours ( 6 years).
\end{abstract}

\section{Introduction}

Thermal stability of high-temperature alloys is continually investigated at Haynes International. As part of a program to study long-term (up to $\sim 6$ years) thermal stability of high temperature alloys, we have reported results for HR-120 ${ }^{\circledR}$ alloy [1] and HR-160 ${ }^{\circledR}$ alloy [2]. This paper will focus on the long-term thermal stability of HAYNES 230 alloy. The 230 alloy was developed in the early 1980 's and since then has been extensively used in components such as combustion cans, transition ducts, flame holders, and honeycomb seals in gas turbine engines [3].

Exposure of high temperature alloys to service conditions may result in microstructural changes, including precipitation of deleterious phases which may affect ductility and toughness, especially during cool down periods. Reduced ductility and toughness may facilitate crack initiation and propagation. Multi-component superalloys are known to form topologically closed-packed (TCP) phases that degrade the ductility and toughness during prolonged service exposures. In order to prevent formation of such phases, the composition of 230 alloy is controlled by the electron vacancy concept, Nv. Subsequent experience has indicated excellent thermal stability of the alloy. Klarstrom [4] reported that after 16,000-hour exposure at $1600^{\circ} \mathrm{F}$, residual Charpy impact toughness for 230 alloy was $26 \mathrm{~J}$ versus $16 \mathrm{~J}$ for $\mathrm{X}$ alloy and $11 \mathrm{~J}$ for 188 alloy, the latter two also being prominent gas turbine alloys. He reported that residual levels of tensile and toughness properties after 16,000 hours of exposure at $1200^{\circ} \mathrm{F}, 1400^{\circ} \mathrm{F}$ and $1600^{\circ} \mathrm{F}\left(649,760\right.$, and $\left.871^{\circ} \mathrm{C}\right)$ were quite respectable. Johnsson [5] carried out aging studies at $775^{\circ} \mathrm{C}, 815^{\circ} \mathrm{C}, 880^{\circ} \mathrm{C}$ and $925^{\circ} \mathrm{C}$ for times ranging from $500 \mathrm{~h}$ to $10,000 \mathrm{~h}$. The samples were examined for oxidation attack, hardness and microstructure. The alloy softened some over time, but the softening was limited, indicating its excellent thermal characteristics. Veverkova et al. in two papers [6,7] reported the microstructural changes in creep and thermally aged 230 alloy. They found a functional relationship between hardness and the Larson-Miller parameter for the alloy. Additionally, it was found that the hardness 
was directly dependent upon the aging temperature, but essentially independent of the aging time in the study up to 20,000 hours of exposure at $750^{\circ} \mathrm{C}, 870^{\circ} \mathrm{C}, 930^{\circ} \mathrm{C}$ and $1050^{\circ} \mathrm{C}$. However, none of the studies besides Ref. [4] reported residual mechanical properties as a result of thermal exposure. The current paper is part of a larger, ongoing study and will concisely review the thermal stability of 230 alloy at exposure times well beyond the previous studies, covering exposure durations of up to 50,000 hours at exposure temperatures of $1200^{\circ} \mathrm{F}, 1400^{\circ} \mathrm{F}$ and $1600^{\circ} \mathrm{F}\left(649,760\right.$, and $\left.871^{\circ} \mathrm{C}\right)$. A more detailed report of the findings of this study will be published elswhere.

\section{Material and Experimental Procedure}

Samples of 230 alloy were taken from $12.7 \mathrm{~mm}\left(1 / 2^{\prime \prime}\right)$ thick production plate material obtained in the mill annealed condition. In this condition, the material had an ASTM grain size of $4 \frac{1}{2}$. The chemistry of the material used in this study is given in Table 1. The long term study consisted of isothermal exposures at 649,760 , and $871^{\circ} \mathrm{C}\left(1200,1400\right.$, and $\left.1600^{\circ} \mathrm{F}\right)$ for periods of 8,000 hours, 20,000 hours, 30,000 hours, and 50,000 hours. The exposures were conducted in a still air environment. After exposure, round tensile samples were machined from the plate, in the process removing the oxidized surface layers. Tensile tests were conducted on the thermally exposed material at room temperature as well as at the exposure temperature (all tensile testing in this study was performed on duplicate samples and the results reported as average values). Fpr baseline reference, tensile testing was also performed at room temperature on material in the mill annealed condition. All tensile samples were oriented in the direction transverse to the rolling direction of the plate. The fracture surfaces of the tensile samples were examined using SEM to determine the fracture mode. Optical microscopy was performed on as-exposed material. Additionally, samples of material exposed for 50,000 hours were subjected to phase analysis. This included SEM/EDS analysis as well as X-ray diffraction of electrolytically extracted residues.

TABLE 1

Chemistry of 230 alloy plate used in this study (wt.\%)

\begin{tabular}{|c|c|c|c|c|c|c|c|c|c|c|c|}
\hline $\mathrm{Ni}$ & $\mathrm{Cr}$ & $\mathrm{W}$ & $\mathrm{Mo}$ & $\mathrm{Fe}$ & $\mathrm{Co}$ & $\mathrm{Mn}$ & $\mathrm{Si}$ & $\mathrm{Al}$ & $\mathrm{C}$ & $\mathrm{La}$ & $\mathrm{B}$ \\
\hline $\mathrm{Bal}$ & 21.42 & 13.88 & 1.26 & 1.11 & 0.25 & 0.51 & 0.39 & 0.31 & 0.10 & 0.008 & 0.004 \\
\hline
\end{tabular}

\section{Results and Discussion}

Microstructural Stability. The microstructural stability of thermally exposed 230 alloy is shown in Fig. 1. Optical micrographs of samples exposed for 8,000 and 50,000h at all three temperatures are presented. The main characteristics of all six micrographs are similar. Large, primary carbides are scattered throughout the structure, while secondary precipitates are seen intragranularly and along grain boundaries. The amount of secondary precipitates has increased significantly over the mill annealed condition [3]. Generally, the secondary precipitates appeared coarser at higher exposure temperatures. Comparing the $8,000 \mathrm{~h}$ and $50,000 \mathrm{~h}$ images for a given temperature, little difference can be seen as a result of the longer exposure duration, although at $871^{\circ} \mathrm{C}$ there appears to be some degradation of the primary carbides in the $50,000 \mathrm{~h}$ exposed sample. No evidence of precipitation of deleterious phases was seen in the optical micrographs.

SEM/EDS. Samples aged at 649,760 , and $871^{\circ} \mathrm{C}$ for $50,000 \mathrm{~h}$ were investigated using an SEM equipped with an EDS. Using this technique, the chemical nature of the primary and secondary phases was determined. The large primary carbides were found to be tungsten-rich, indicating that these are likely $\mathrm{M}_{6} \mathrm{C}$ carbides. Secondary precipitates were generally chromium-rich, suggesting that they are $\mathrm{M}_{23} \mathrm{C}_{6}$ carbides. No precipitates were found with chemistries inconsistent with these two carbide phases. 
Extraction/X-ray Diffraction. X-ray diffraction was performed on extracted residues taken from the samples aged at 649,760 , and $871^{\circ} \mathrm{C}$ for $50,000 \mathrm{~h}$. The results were consistent with the optical micrographs and the SEM/EDS characterization. In addition to the fcc matrix, only $\mathrm{M}_{23} \mathrm{C}_{6}$ and $\mathrm{M}_{6} \mathrm{C}$-type carbides were identified in the resulting pattern. No unidentified peaks were observed which could be associated with a deleterious phase such as sigma, etc.

Room Temperature (RT) Tensile Properties. The room temperature tensile elongation of thermally exposed 230 alloy is shown in Fig. 2 as a function of exposure duration. Also shown is a dotted line indicating the baseline, that is, the initial elongation value in the mill annealed condition. For exposure temperatures of 649 and $760^{\circ} \mathrm{C}$, an initial decrease in elongation from $52 \%$ to the mid30 's $\%$ was observed after $8,000 \mathrm{~h}$. With continued thermal exposure no significant further decrease in elongation occurred at either exposure temperature. In both cases, the elongation remained greater than $30 \%$ even after $50,000 \mathrm{~h}$. At $871^{\circ} \mathrm{C}$, a similar initial decrease in elongation from $52 \%$ to $36 \%$ was seen after $8,000 \mathrm{~h}$. At longer exposure durations the elongation decreased at a more gradual rate, eventually falling to $25.2 \%$ after $50,000 \mathrm{~h}$. The observation that the RT elongation decreased more sharply after the first $8,000 \mathrm{~h}$ of exposure at all three temperatures was consistent with the microstructural observations described above, where after the formation of secondary precipitates during the first $8,000 \mathrm{~h}$ the microstructure remained effectively stable. Further, in the study by Klarstrom [4] it was found that most of the effects of long term thermal exposure were observed in as short as $100 \mathrm{~h}$.

Also shown in Fig. 2 is the RT yield strength of 230 alloy as a function of exposure temperature. At $649^{\circ} \mathrm{C}$, the yield strength increased modestly after $8,000 \mathrm{~h}$ and then increased only very slightly more with continued thermal exposure. At $760^{\circ} \mathrm{C}$, the yield strength also increased modestly after $8,000 \mathrm{~h}$, but then very slightly decreased with increasing thermal exposure. For the $871^{\circ} \mathrm{C}$ exposure, the yield strength increased very slightly after $8,000 \mathrm{~h}$. With continued exposure, the yield strength dropped to approximately the baseline value and then remained virtually unchanged. In general, the effect of thermal exposure on the yield strength of 230 alloy could be described as minimal.

RT Fracture Mode. The fracture mode of the RT tensile samples exposed for $50,000 \mathrm{~h}$ was characterized by SEM. The fractographs are shown in Fig. 3. For all three temperatures, the fracture mode exhibited some intergranular character, but was generally ductile showing evidence of microvoid coalescence.

Charpy Impact Toughness. The Charpy impact toughness of 230 alloy is shown in Fig. 4 as a function of exposure temperature. For all three exposure temperatures, the impact toughness dropped noticeably after the first $8,000 \mathrm{~h}$. At longer exposure durations, the change in impact toughness was considerably slower. The samples exposed at $649^{\circ} \mathrm{C}$ experienced the least drop in impact toughness, decreasing from $73 \mathrm{~J}$ to $43 \mathrm{~J}$ after the first $8,000 \mathrm{~h}$ and to $35 \mathrm{~J}$ after $50,000 \mathrm{~h}$. In contrast, the toughness of samples exposed at $760^{\circ} \mathrm{C}$ decreased to $25 \mathrm{~J}$ after the first $8,000 \mathrm{~h}$ and actually slightly increased to $28 \mathrm{~J}$ after $50,000 \mathrm{~h}$. The samples exposed at $871^{\circ} \mathrm{C}$ decreased in toughness to $29 \mathrm{~J}$ after $8,000 \mathrm{~h}$ and to $20 \mathrm{~J}$ after $50,000 \mathrm{~h}$.

Elevated Temperature Tensile Properties. To get a better understanding of the impact of longterm thermal exposure on the elevated temperature properties of 230 alloy, tensile tests were performed on the exposed materials at the actual exposure temperature. The results are shown in Fig. 5. (Note that baseline elevated temperature tensile data is not available for comparison since this was not part of the original test plan.) The elongation values were found to be very high for all three exposure temperatures and to be only weakly dependent on the exposure duration. The lowest values were observed at $649^{\circ} \mathrm{C}$, but even at this temperature the tensile elongation was $35 \%$ after a $50,000 \mathrm{~h}$ exposure. At 760 and $871^{\circ} \mathrm{C}$, the elongations were greater than $65 \%$ for all exposure durations. The ductility of 230 alloy at operating temperatures is clearly not significantly degraded by thermal exposure. 
Similarly, the yield strength values at the three exposure temperatures exhibit almost no change from 8,000 to $50,000 \mathrm{~h}$, confirming again that the elevated properties of 230 alloy are relatively unaffected by thermal exposure (see Fig. 5).

\section{Summary and Conclusions}

Long-term thermal exposures of 230 alloy up to 50,000h were conducted at temperatures of 649 , 760 , and $871^{\circ} \mathrm{C}\left(1200,1400\right.$, and $\left.1600^{\circ} \mathrm{F}\right)$ to determine their effect on the microstructure and mechanical properties of the alloy. The resulting microstructures were found to contain only $\mathrm{M}_{23} \mathrm{C}_{6}$ and $\mathrm{M}_{6} \mathrm{C}$-type carbides regardless of exposure temperature, with no evidence of any deleterious phases. The effects of the thermal exposures on the RT tensile elongation and Charpy impact toughness were similar. Exposures at 649 and $760^{\circ} \mathrm{C}$ resulted in a drop of both properties after $8,000 \mathrm{~h}$. However, at longer exposure durations no significant further decreases were observed. At $871^{\circ} \mathrm{C}$, the RT elongation and Charpy toughness values also dropped significantly in the first $8,000 \mathrm{~h}$. Longer exposure at $871^{\circ} \mathrm{C}$ resulted in a further, but much more modest decrease in values. For all three exposure temperatures, the decreased RT elongation after thermal exposure was correlated to the formation of secondary $\mathrm{M}_{23} \mathrm{C}_{6}$ carbides. It is crucial to point out that for all three exposure temperatures the RT elongation and Charpy impact toughness values of 230 alloy never dropped below $25 \%$ and $20 \mathrm{~J}$, respectively, even after the full $50,000 \mathrm{~h}$ thermal exposures and that the tensile fracture mode remained ductile. These retained ductility values are quite high compared to other structural high-temperature alloys in its class and are consistent with the fact that no deleterious phases were observed in the thermally exposed microstructures.

For samples tested at the exposure temperature, tensile ductilities were found to be very high, being greater than $35 \%$ for samples exposed at $649^{\circ} \mathrm{C}$, and greater than $65 \%$ for samples exposed at 760 and $871^{\circ} \mathrm{C}$. This is consistent with other alloys, such as HR-120 alloy, where loss in ductility due to thermal exposure was evident only when tested at RT [1].

In general, it was found that the long-term thermal stability of 230 alloy is outstanding in terms of both strength and ductility, making it an excellent candidate for use in critical high temperature applications.

\section{References}

[1] L. M. Pike and S.K. Srivastava: in Properties and Performance of High Temperature Alloys and Castings, ed. by Qiang Feng, et al., TMS Publication, Warrendale, PA (2007).

[2] V.P. Deodeshmukh and S.K. Srivastava: J Mater Design Vol. 31 (2010), pp. 2501-9.

[3] D.L. Klarstrom: in Materials Design Approaches and Experiences, ed. by J. C. Zhao, et al., TMS Publication, Warrendale, PA (2001), pp. 297-307.

[4] D. L. Klarstrom: CORROSION 94, Paper No. 407, NACE Intl., Houston, TX (1994).

[5] Andreas Johnsson: ABB Report TRM 54/98 (1998).

[6] J. Veverkova et al.: in Proc. of the 7th Int. Charles Parsons Turbine Conf., ed. by A. Strang et al., IOM, London (2007), pp. 162-172.

[7] J. Veverkova et al.: in Superalloys 2008, ed. By Roger C. Reed et al., TMS Publication, Warrendale, PA (2008), pp. 479-488. 
(a)

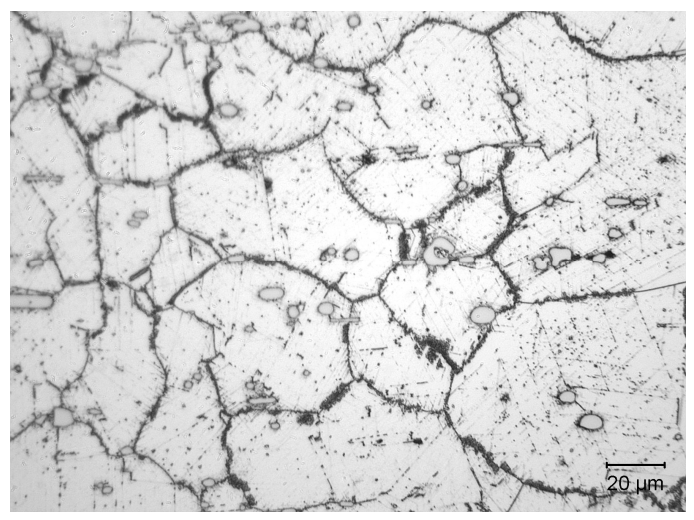

(c)

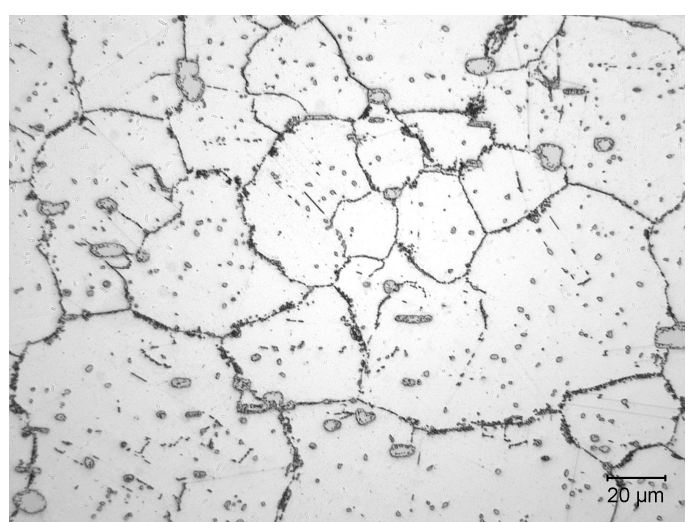

(e)

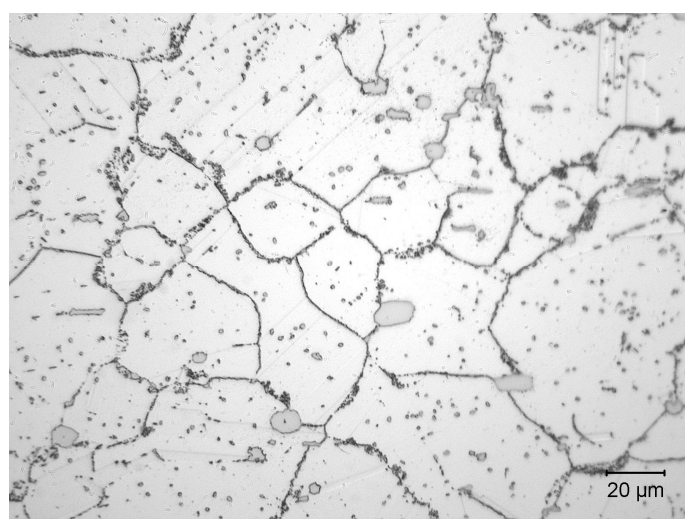

(b)

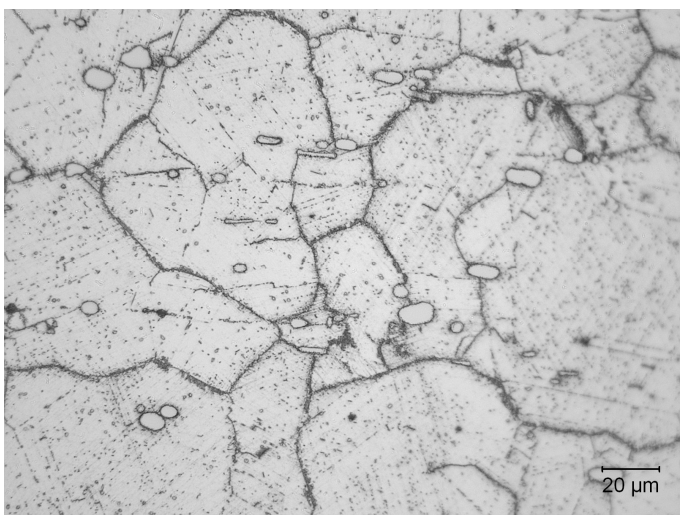

(d)

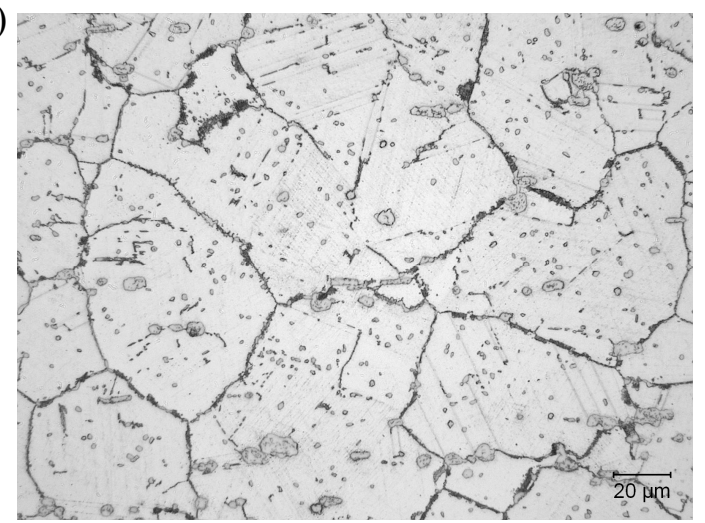

(f)

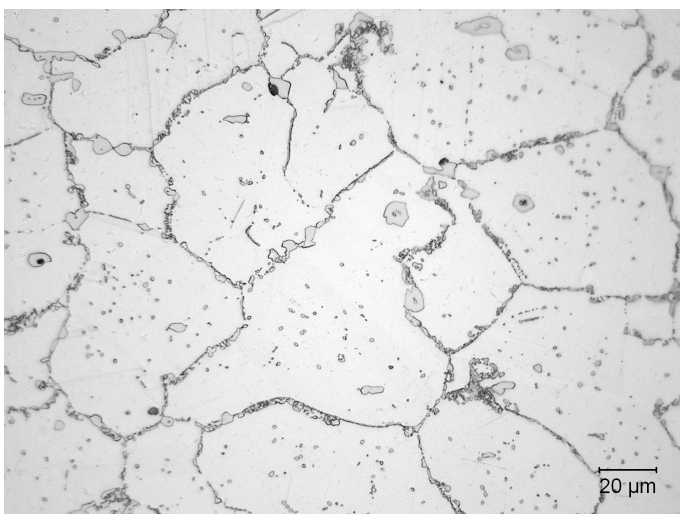

Fig. 1230 alloy after long term exposures at: (a) \& (b): $649^{\circ} \mathrm{C}$; (c) $\&$ (d): $760^{\circ} \mathrm{C}$; (e) \& (f) $871^{\circ} \mathrm{C}$.

The images on the left and right correspond to 8,000 and 50,000 $\mathrm{h}$ exposures, respectively.

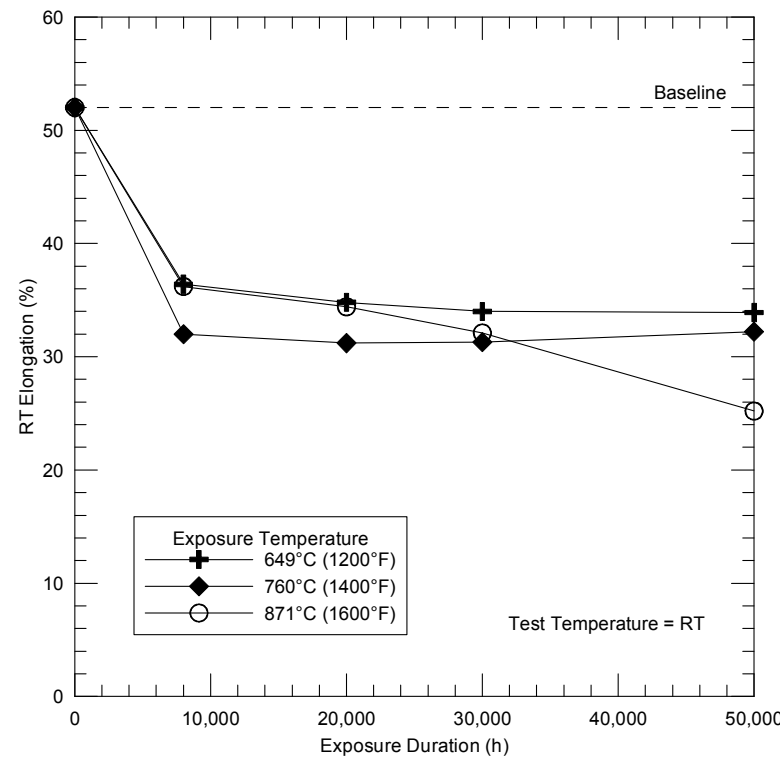

(a)

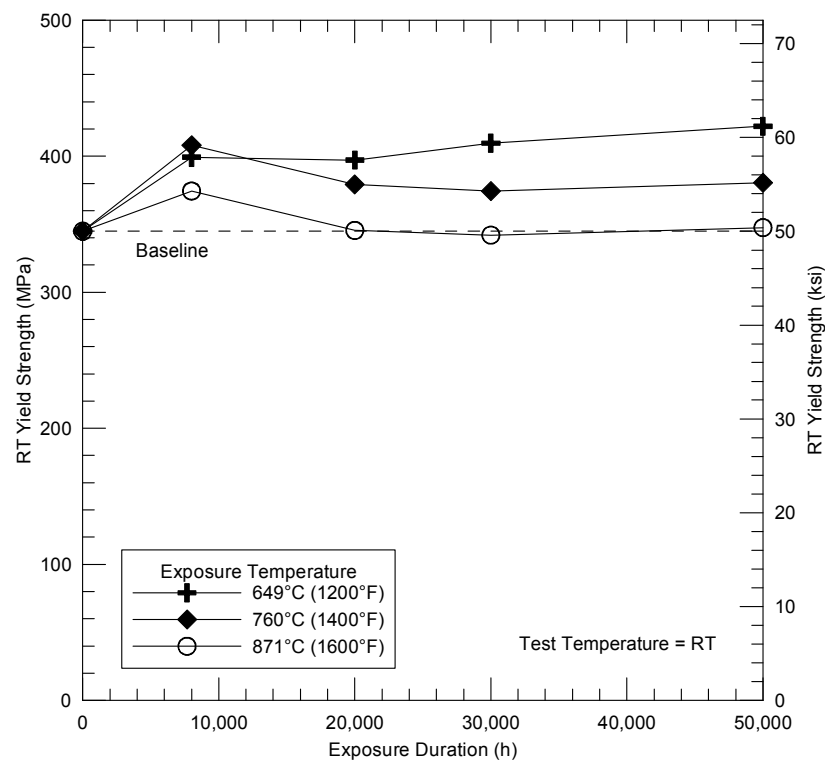

(b)

Fig. 2 The (a) elongation and (b) yield strength at RT of 230 alloy as a function of exposure duration. 


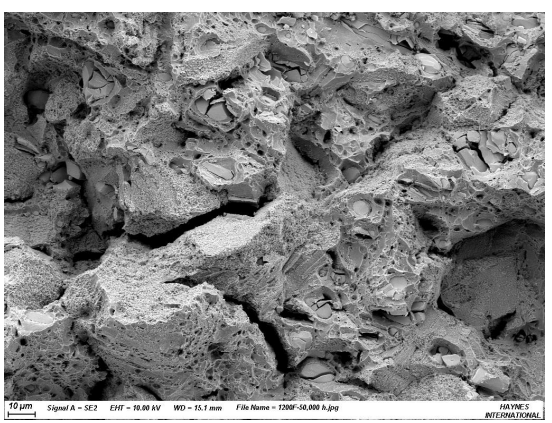

(a)

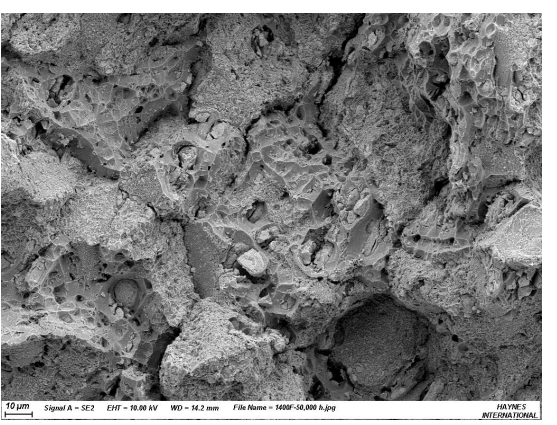

(b)

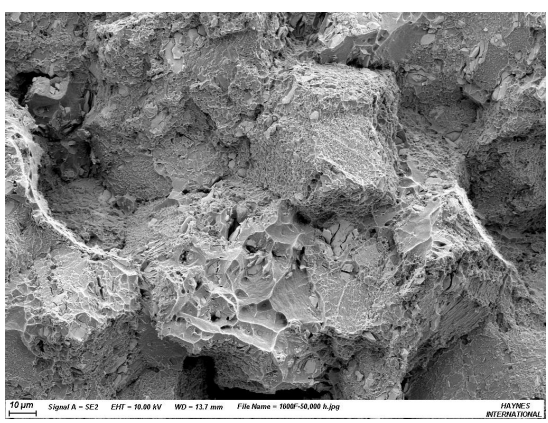

(c)

Fig. 3 The RT fracture mode of 230 alloy exposed for $50,000 \mathrm{~h}$ at: (a) $649^{\circ} \mathrm{C}$, (b) $760^{\circ} \mathrm{C}$, and (c) $871^{\circ} \mathrm{C}$.

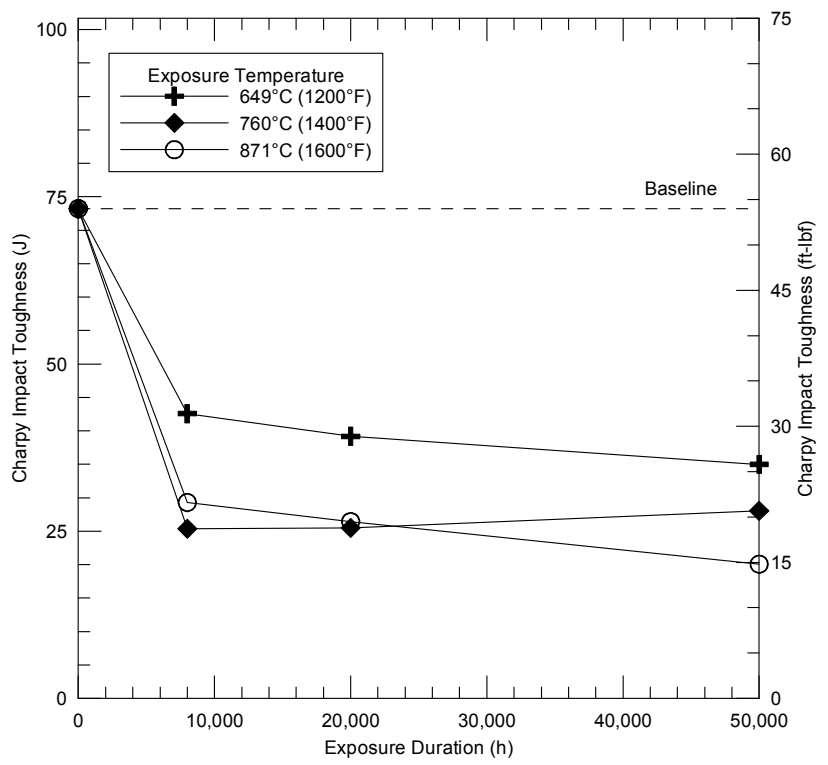

Fig. 4 The Charpy impact toughness of 230 alloy as a function of exposure duration.

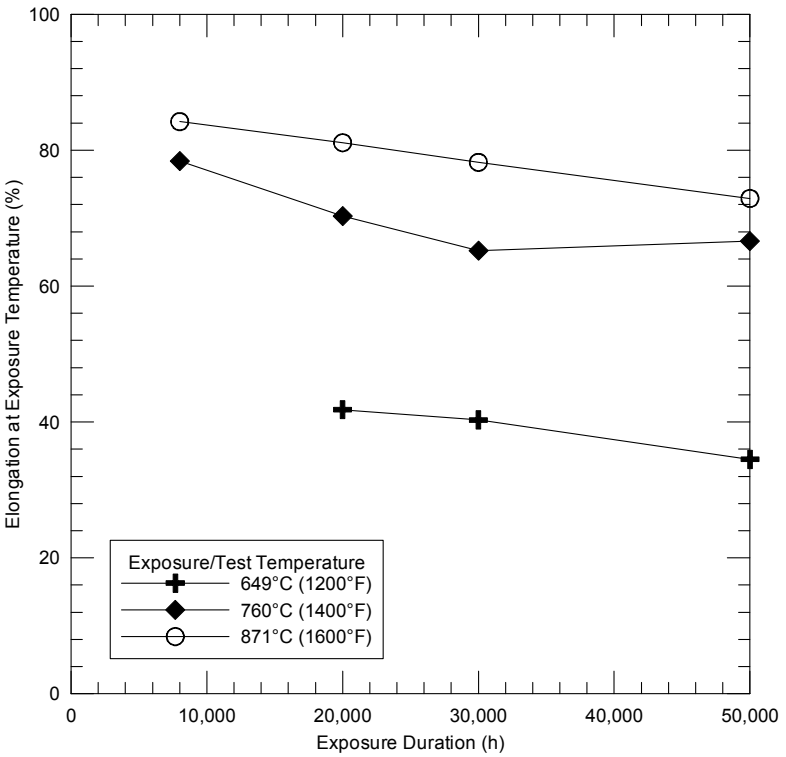

(a)

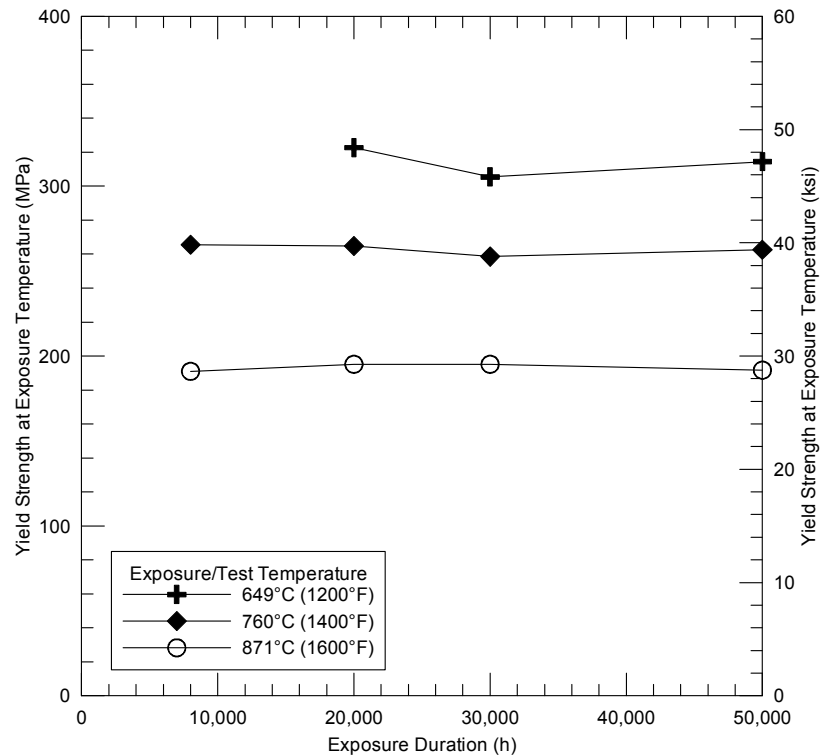

(b)

Fig. 5 The (a) elongation and (b) yield strength at the exposure temperature of thermally exposed 230 alloy as a function of exposure duration. 